\title{
Antimicrobial activity of an L-amino acid oxidase isolated from Bothrops leucurus snake venom
}

Torres AFC (1), Dantas RT (2), Menezes RRPPB (1) Toyama MH (3), Filho ED (4), Oliveira MF (1), Nogueira NAP (1), Oliveira MR (5), Monteiro HSA (2), Martins AMC (1)

(1) Department of Clinical and Toxicological Analysis, School of Pharmacy, Federal University of Ceará, Fortaleza, Ceará State, Brazil; (2) Department of Physiology and Pharmacology, Federal University of Ceará, Fortaleza, Ceará State, Brazil; (3) Laboratory of Cell Biology and Chemistry for Proteins and Peptides, São Paulo Experimental Coast Campus, São Paulo State University (UNESP - Univ Estadual Paulista), São Vicente, São Paulo State, Brazil; (4) Department of Biochemistry, Institute of Biology, State University of Campinas, UNICAMP, Campinas, São Paulo State, Brazil; (5) Department of Molecular Biology, Center of Exact Sciences and Nature, Federal University of Paraíba, João Pessoa, Paraíba State, Brazil.

\begin{abstract}
Some snake venom proteins present enzymatic activities, such as L-amino acid oxidase (LAAO). The aim of this paper was to investigate the effect of Bothrops leucurus total venom (BleuTV) and its fraction LAAO (BleuLAAO) on bacteria, yeast, and promastigote forms of Leishmania amazonensis and Leishmania chagasi, and epimastigote forms of Trypanosoma cruzi. BleuTV was isolated with a Protein Pack 5PW ${ }^{\circledR}$ (Waters Corporation, USA), and several fractions were obtained. BleuLAAO was purified to high molecular homogeneity, and its $\mathrm{N}$-terminal amino acid sequence shared a high degree of amino acid conservation with other LAAOs. BleuTV inhibited Staphylococcus aureus growth in a dose-dependent manner, with a minimum inhibitory concentration (MIC) of $25 \mu \mathrm{g} / \mathrm{mL}$, which corresponded to its minimum lethal concentration (MLC). BleuTV also inhibited the growth of promastigote forms of $L$. chagasi and $L$. amazonensis, with respective $\mathrm{IC}_{50}$ values of $1.94 \mu \mathrm{g} / \mathrm{mL}$ and $5.49 \mu \mathrm{g} / \mathrm{mL}$. Furthermore, it repressed $T$. cruzi growth with an $\mathrm{IC}_{50}$ of $1.14 \mu \mathrm{g} /$ $\mathrm{mL}$. However, BleuLAAO did not inhibit the growth of the microorganisms studied and was not toxic to macrophages. BleuTV had low toxicity against macrophages at the concentrations studied. In conclusion, whole venom from Bothrops leucurus inhibited the growth of some microorganisms, including S. aureus, Leishmania sp., and T. cruzi.
\end{abstract}

Key words: L-amino oxidase, Bothrops leucurus, antimicrobial activity.

\section{INTRODUCTION}

Members of the genus Bothrops are present in several ecosystems and include approximately 20 species. The main snakes of this genus are $B$. jararaca, B. jararacussu, B. moojeni, B. asper, $B$. alternatus, $B$. marajoensis and B. leucurus (1).

Snake venom contains numerous components of biological and/or biotechnological value. Venom is a complex mixture that varies in proportions and characteristics among different species and contains both non-protein and protein components with different structures and specific biochemical activities $(2,3)$. The major protein components of the venom are neurotoxins, cardiotoxins, lectins, disintegrins, natriuretic peptides, proteases, phospholipases, phosphodiesterases, nucleotidases, and L-amino acid oxidases (2). Venom enzymes induce various pharmacological effects including neurotoxic, myotoxic, cardiotoxic, hemorrhagic, hemolytic, procoagulant and anticoagulant $(4,5)$.

L-Amino acid oxidase (L-amino acid: $\mathrm{O}_{2}$ oxidoreductase, EC 1.4.3.2) is a flavoenzyme that catalyzes the oxidative deamination of an L-amino acid substrate into an $\alpha$-keto acid with the production of ammonia and hydrogen peroxide. LAAO is the only FAD-dependent oxidase found in snake venom, and venom toxicity may be related to the hydrogen peroxide 
generated during reoxidation of the transiently reduced flavin cofactor by molecular oxygen $(6,7)$.

Various venoms and toxins show antibacterial activity, such as miotoxin II from B. moojeni and venom from $B$. neuwiedi pauloensis $(8,9)$. Several bothropic venoms inhibit growth of some intracellular parasites, such as Leishmania sp. and Trypanosoma cruzi. Crotalus durissus venoms inhibit parasite growth; however, Crotalus durissus colillineatus venom increases the promastigote growth rate (10). Moreover, $B$. jararaca venom inhibits promastigote forms of $L$. amazonensis and epimastigote forms of T. cruzi, with rupture of the membrane and mitochondrial disruption (11).

In light of the potential biological activities of animal venoms and toxins and the need to understand the molecules involved in the hostparasite interaction, the aim of this paper was to study the effect of $B$. leucurus venom and its fraction L-amino acid oxidase (LAAO) on bacteria, yeast, promastigote forms of $L$. amazonensis and L. chagasi, and epimastigote forms of T. cruzi.

\section{MATERIAL AND METHODS}

\section{Reagents and Venom}

The venom was obtained from Butatan Institute, in São Paulo city, SP, Brazil. Chemicals and reagents employed in this work were purchased from Sigma-Aldrich (Sigma Chemical Co., USA), Applied Biosystems, Pierce and Bio $\operatorname{Rad}($ USA).

\section{Purification of L-amino Acid Oxidase from $B$. leucurus Venom}

LAAO from $B$. leucurus whole venom was purified by two chromatographic steps. First, the whole venom was fractionated by affinity chromatography with immobilized lactose as the stationary phase (Pierce, USA). Approximately $100 \mathrm{mg}$ of whole venom previously dissolved in Tris-buffered saline (TBS, $0.05 \mathrm{M}, \mathrm{pH}$ 7.8) was centrifuged and filtered with 0.22 $\mu \mathrm{m}$ filters. The same buffer was used for equilibration of the chromatographic column. The chromatographic profile was determined by measuring the absorbance at $280 \mathrm{~nm}$. LAAO activity was measured with a microplate assay (12). The first fraction that eluted in the first chromatographic step, which contained the majority of LAAO activity, was subjected to a second chromatographic step with a ProteinPak DEAE 5PW ${ }^{\oplus}$ (Waters Corporation, USA). Proteins were eluted at a constant flow rate of 1.0 $\mathrm{mL} /$ minute with a linear gradient $(0.05$ to $1.0 \mathrm{M})$ of ammonium bicarbonate, and the elution profile was monitored at $280 \mathrm{~nm}$. The concentrated fraction was then recovered and stored at $-20^{\circ} \mathrm{C}$. PAGE-SDS electrophoresis was conducted as previously described (13).

\section{Microplate Assay for L-amino Acid Oxidase}

The assay was conducted in triplicate in a 96-well microplate; $10 \mu \mathrm{L} /$ well of the enzyme solution and $90 \mu \mathrm{L} /$ well of the substrate solution were added to start the reaction. The standard reaction mixture contained $250 \mathrm{mM}$ L-leucine, $2 \mathrm{mM}$ o-phenylenediamine (OPD), $0.81 \mathrm{U} / \mathrm{mL}$ horseradish peroxidase and LAAO in $50 \mathrm{mM}$ Tris- $\mathrm{HCl}$ buffer $(\mathrm{pH} 8.0)$ in a total volume of 100 $\mu \mathrm{L} /$ well. After incubation at $37^{\circ} \mathrm{C}$ for 60 minutes, the reaction was terminated by adding $50 \mu \mathrm{L}$ of 2 $\mathrm{M} \mathrm{H}_{2} \mathrm{SO}_{4}$. The absorbance of the reaction mixture was measured in a SpectraMax Microplate Reader $^{\circledast}$ (Molecular Devices, USA) at $480 \mathrm{~nm}$ $(12,14)$. The enzyme activity was measured by the increase in absorbance after the incubation time and compared with LAAO activity from other venoms. Hydrogen peroxide standards were used and linear regression of the data was calculated with Origin 5.0 $0^{\circ}$ software (Microcal, USA). LAAO activity was expressed as nmoles $\mathrm{H}_{2} \mathrm{O}_{2} /$ minute.

\section{N-terminal Amino Acid Sequence}

The N-terminal sequence of LAAO was determined following published protocols (15). Briefly, $10 \mathrm{mg}$ of purified protein was dissolved in $200 \mu \mathrm{L}$ of $6 \mathrm{M}$ guanidine (final $\mathrm{pH}$ 8.15). Nitrogen was flushed over the top of the protein solution for 15 minute, and the protein was then reduced with dithiothreitol (DTT, $6 \mathrm{M}, 200 \mu \mathrm{L}$ ) and carboxymethylated with ${ }^{14} \mathrm{C}$-iodoacetic acid and cold iodoacetic acid. Nitrogen was again flushed over the surface of the solution and the reaction tube was sealed. This solution was incubated in the dark at $37^{\circ} \mathrm{C}$ for one hour and desalted with a C4 reverse phase HPLC column and the same elution buffer used in the protein purification. The eluted, reduced, and carboxymethylated (RC) proteins were then lyophilized and stored 
at $-20^{\circ} \mathrm{C}$. N-terminal sequencing of the reduced and carboxymethylated proteins was conducted using a Procise $\mathrm{f}$ automatic sequencer ${ }^{\circledast}$ (USA). Phenylthiohydantoin (PTH) amino acids were identified by comparing their retention times with those of $20 \mathrm{PTH}$ amino acid standards on an Applied Biosystems model 450 Microgradient $\mathrm{PTH}^{\oplus}$ analyzer (USA). Peptides containing ${ }^{14} \mathrm{C}-\mathrm{CM}$-Cys were monitored for radioactivity with a Beckman L-250 ${ }^{\circ}$ liquid scintillation counter (USA). The N-terminal analysis of the protein was performed with ClustalW (http:// www.clustal.org/).

\section{Antimicrobial Activity of Bothrops leucurus Venom and Fraction}

Whole venom (BleuTV; $2 \mathrm{mg} / \mathrm{mL}$ ) and L-amino acid oxidase (BleuLAAO; $2 \mathrm{mg} / \mathrm{mL}$ ) were dissolved in sterile phosphate-buffered saline, $\mathrm{pH} 7.4$.

The antimicrobial potential of the whole venom and LAAO was determined by the disk-diffusion method with modifications (16). Five pure microbial cultures (Salmonella choleraesuis subsp. choleraesuis serotype choleraesuis ATCC 10708, Staphylococcus aureus ATCC 6538P, Escherichia coli ATCC 11229, Pseudomonas aeruginosa ATCC 15442 and Candida albicans ATCC 10231 all donated by the Laboratory for Reference Materials of the Oswaldo Cruz Foundation, FIOCRUZ), as well as the refrigerated agar stock were added to brain heart infusion (BHI) broth and incubated at $35^{\circ} \mathrm{C}$ until they reached a visible turbidity equivalent to 0.5 on the McFarland scale (approximately $10^{8} \mathrm{CFU} / \mathrm{mL}$ ).

The bacterial inoculums were spread with a sterile cotton swab on the surface of sterile Mueller-Hinton agar (Merck, Germany) for bacteria or sterile Sabouraud-dextrose agar (Merck, Germany) for yeast. After five minutes, wells were made in the agar (5-mm diameter) using a sterile punch. In these wells, $25 \mu \mathrm{L}$ of varying concentrations $(2,1,0.5,0.25$ and 0.125 $\mathrm{mg} / \mathrm{mL}$ ) of venom or the venom fraction LAAO were added. Commercial antimicrobials $(2 \mathrm{mg} /$ $\mathrm{mL}$ amikacin and $1.2 \mathrm{mg} / \mathrm{mL}$ ketoconazole) were used as positive controls, and the sample diluent (PBS, $\mathrm{pH} 7.4$ ) was used as a negative control. After incubation at $35^{\circ} \mathrm{C}$ for 18 hours, the zone of inhibition was recorded in millimeter diameters.

\section{Determination of Minimum Inhibitory Concentration (MIC)}

The MIC was determined using a broth microdilution method as reported by Hecht et al. (17) with modifications. The venom and fractions were prepared as previously described (section: "Antimicrobial Activity of Bothrops leucurus Venom and Fraction), and several concentrations $(200,100,50,25$ and $12.5 \mu \mathrm{g} / \mathrm{mL})$ were used. The microbial strains were subcultured, and microbial density was adjusted as previously described. The cultures were diluted to 1:100 $\left(\sim 1.5 \times 10^{6} \mathrm{CFU} / \mathrm{mL}\right)$. An inoculum of $125 \mu \mathrm{L}$ of microbial culture was added to $25 \mu \mathrm{L}$ of each concentration of venom or venom fraction in BHI broth $(100 \mu \mathrm{L})$ for bacteria or Sabourauddextrose broth for C. albicans in 96-well plates. For the negative control, wells contained sterile PBS (pH 7.4) instead of venom or fractions. For the positive controls (growth inhibition), wells contained culture medium, an antimicrobial agent (amikacin for bacteria and ketoconazole for yeast), and an inoculum of microorganisms. The plates were incubated at $35^{\circ} \mathrm{C}$ for 24 hours, and inhibition of microorganism growth was determined by measuring the absorbance at 490 $\mathrm{nm}$. The MIC was assessed based on the lowest concentration of sample required to inhibit microbial growth (detected by a lack of visible turbidity). Three independent experiments were performed in triplicate.

\section{Determination of Minimum Lethal Concentration (MLC)}

For assays of minimum lethal concentration, $25-\mu \mathrm{L}$ aliquots were removed from wells that did not contain visible turbidity as previously described (section: "Antimicrobial Activity of Bothrops leucurus Venom and Fraction) and were placed on plate count agar (for bacteria) or Sabouraud-dextrose agar (for C. albicans) by the pour-plate method. After incubation at $35^{\circ} \mathrm{C}$ for 24 hours, colonies were counted. The concentration of samples that resulted in growth $\leq 0.1 \%$ of initial inoculum $\left(1.5 \times 10^{6} \mathrm{CFU} / \mathrm{mL}\right)$ was recognized as the MLC (17).

\section{Leishmanicidal Effects of B. leucurus Venom and Fraction}

The promastigote forms of $L$. amazonensis (MHOM/IFLA/BR/67/PH8) and L. chagasi (MCAN/BR/99/JP15) were used in ours 
experiments. The parasites were cultivated in $\mathrm{NNN} / \mathrm{Schneider}$ medium supplemented with $20 \%$ fetal bovine serum (FBS), penicillin $(1000 \mathrm{U} / \mathrm{mL})$ and streptomycin $(50 \mu \mathrm{g} / \mathrm{mL})$. The cultures were incubated at $26^{\circ} \mathrm{C}$ until they reached stationary growth phase (18). Cytotoxicity was evaluated for $1 \times 10^{6}$ cells $/ \mathrm{mL}$ of parasite culture in the presence of various concentrations of the venom $(200,100,50,25$, $12.5,6.25,3.12$ and $1.56 \mu \mathrm{g} / \mathrm{mL})$ or fraction $(6.25$, $3.12,1.56,0.78$ and $0.39 \mu \mathrm{g} / \mathrm{mL})$. As a negative control, cells were cultivated in the absence of B. leucurus venom or fraction. After 72 hours, qualitative and quantitative analyses of the cells were performed, and the promastigote forms were quantified in a Neubauer chamber. The motion and characteristic form of promastigotes were observed by optical microscopy (40x).

\section{Trypanocidal Effects of B. leucurus Venom and Fraction}

The epimastigote form of the $\mathrm{Y}$ strain of $T$. cruzi was cultured in liver infusion tryptose (LIT, Difco, USA) medium according to Camargo (19). Hemin was replaced by hemoglobin. The parasites were kept at $26^{\circ} \mathrm{C}$ and the medium was replaced every 5 to 6 days until the concentration of parasites in the logarithmic phase reached a density of approximately $5 \times 10^{7}$ to $10 \times 10^{8}$ parasites $/ \mathrm{mL}$. Parasites were quantified in a Neubauer chamber after dilution in formaldehyde $(2 \% \mathrm{v} / \mathrm{v}$, in PBS). To evaluate the trypanocidal activity of different concentrations of venom or the fraction $(200,100,50,25,12.5,6.25,3.12$ and $1.56 \mu \mathrm{g} / \mathrm{mL}$ ), the parasites were subcultured in 96-well microplates at a density of $1 \times 10^{6}$ parasites $/ \mathrm{mL}$ at $26^{\circ} \mathrm{C}$ for five days. For a negative control, parasites were cultured in PBS $(\mathrm{pH}$ 7.4). After the incubation period, the cells were quantified in a Neubauer chamber. The motion and characteristic form of epimastigotes were observed by optical microscopy (40x).

\section{Cytotoxicity in Murine Macrophages}

Macrophageswere obtained from the peritoneal cavity of Swiss female mice and cultivated in RPMI-1640 medium supplemented with FBS (10\%), penicillin, and streptomycin, and $1 \times 10^{6}$ cells $/ \mathrm{mL}$ were seeded in 96-well microplates for two hours at $37^{\circ} \mathrm{C}$ with $5 \% \mathrm{CO}_{2}$. Cells were washed twice with medium at $37^{\circ} \mathrm{C}$ and further incubated with venom or venom fraction at the highest concentration $(200 \mu \mathrm{g} / \mathrm{mL})$ for 24 hours at $37^{\circ} \mathrm{C}$. The viability of the macrophages was determined using an MTT (3-(4.5-dimethylthiazol-2-yl)2.5-diphenyltetrazolium bromide) assay (20). After the incubation, $100 \mu \mathrm{L}$ of the medium was aspirated, $10 \mu \mathrm{L}$ of MTT was added to the wells, and the plate was incubated for four hours. Following this incubation, $90 \mu \mathrm{L}$ of a solution of $10 \%$ sodium dodecyl sulfate hydrochloride (SDS/ $\mathrm{HCl}$ ) was added to solubilize the MTT-formazan product. After 17 hours, the plate was read with a microplate reader at $570 \mathrm{~nm}$. All measurements were performed in triplicate.

\section{RESULTS}

\section{LAAO Purification from B. leucurus Venom}

LAAO from B. leucurus venom was purified as non-binding material from a lactose affinity column used to purify lectin that was eluted by a TBS buffer containing $0.3 \mathrm{M}$ galactose (Figure 1 - A). The non-binding material containing the LAAO fraction was then subjected to DEAE chromatography on a DEAE 5PW HPLC column (Figure 1 - B). The LAAO from B. leucurus was purified to high molecular homogeneity after this last chromatographic step, and its molecular weight was estimated at approximately $80 \mathrm{kDa}$ by SDS-PAGE (Figure $1-\mathrm{C}$ ). The N-terminal amino acid sequence of the LAAO isolated from $B$. leucurus was highly conserved with other LAAO from other sources (Figure $1-\mathrm{D})$. The enzymatic activities estimated at $480 \mathrm{~nm}$ (Vo 480 $\mathrm{nm}$ ) of B. leucurus LAAO, Bothrops pirajai LAAO and Crotalus durissus cascavella LAAO were 0.31 $\pm 0.06,0.36 \pm 0.04$ and $0.21 \pm 0.03$. The enzymatic activity of LAAO from Bothrops leucurus was therefore intermediate that of the LAAOs from Crotalus durissus cascavella and Bothrops pirajai. Two-dimensional electrophoresis revealed that the molecular weight of the protein was $80 \mathrm{kDa}$ and its pI was approximately 5.3.

\section{Antibacterial Activity}

Antibacterial activity was evaluated by the presence of an inhibition zone after inoculation in Mueller-Hinton agar for bacteria or Sabourauddextrose agar for C. albicans. Inhibition zones were determined by a radial diffusion assay. BleuTV inhibited the growth of $S$. aureus (Figure $2-\mathrm{A}$ and $\mathrm{B}$ ). BleuLAAO did not cause any degree of inhibition of the strains studied. 
The microdilution method was used to determine the MIC and MLC for BleuTV. MIC and MLC values for the venom were $25 \mu \mathrm{g} / \mathrm{mL}$. When compared with amikacin (MIC $=25 \mu \mathrm{g} / \mathrm{mL}$ and $\mathrm{MLC}=50 \mu \mathrm{g} / \mathrm{mL}$ ), BleuTV was significantly more efficient (Figure 3).

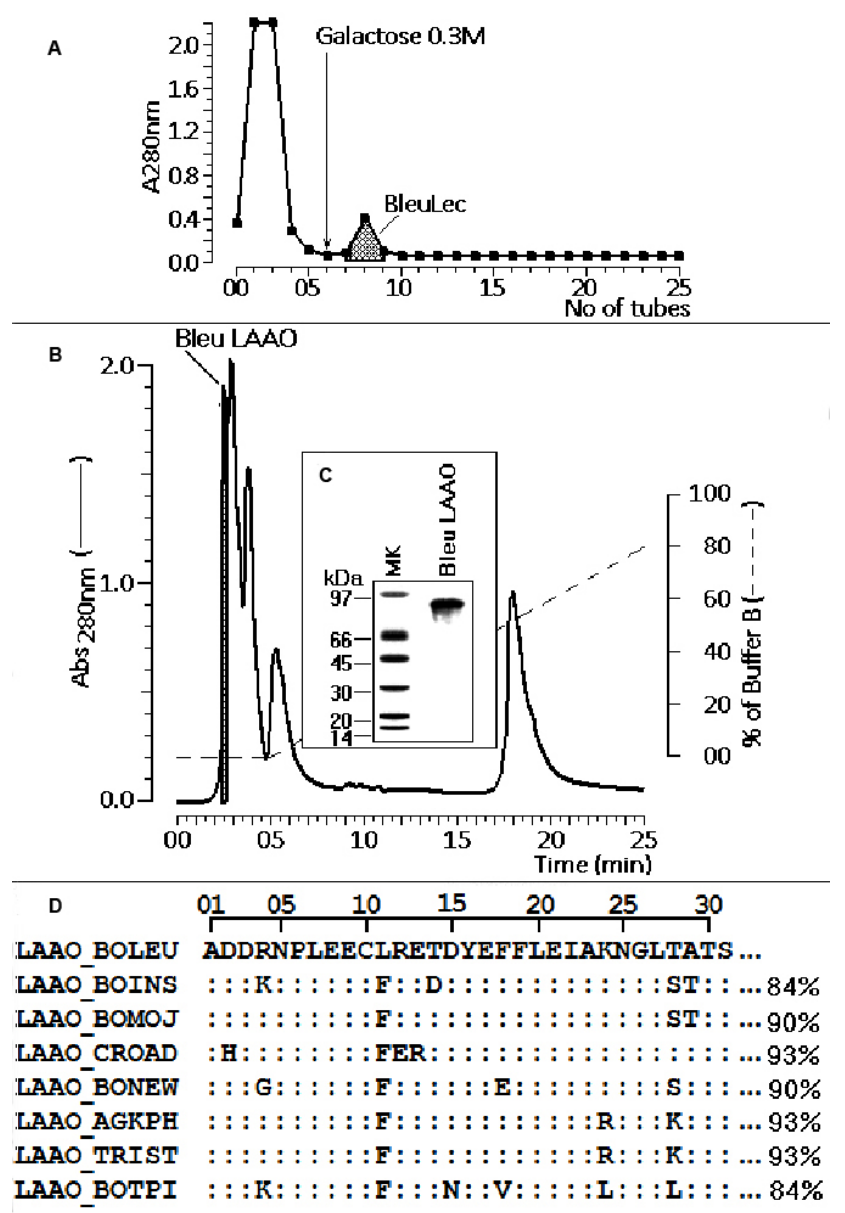

Figure 1. (A) The chromatographic profile of the fractionation of whole venom by lectin affinity chromatography; the non-binding sample was eluted using only TBS buffer, and lectin was eluted using TBS with galactose. (B) The chromatographic profile of the fractionation of LAAO from $B$. leucurus. (C) Tricine SDS-PAGE analysis of BleuLAAO. (D) The $\mathrm{N}$-terminal sequence of this LAAO compared with other LAAO isoforms (LAAO_BOLEU: LAAO from $B$. leucurus; LAAO_BOINS: LAAO from $B$. insularis; LAAO_BOMOJ: LAAO from B. moojeni; LAAO_ CROAD: LAAO from $C$. adamanteus; LAAO_BONEW: LAAO from B. neuwiedi; LAAO_AGKPH: LAAO from Agkistrodon piscivorus; LAAO_TRIST: LAAO from Trimeresurus stejnegeri; LAAO_BOTPI: LAAO from Bothrops pirajai).

\section{Leishmanicidal and Trypanocidal Activity}

BleuTV inhibited the promastigote forms of L. amazonensis and L. chagasi after 72 hours of culture (Figure 4), $\mathrm{IC}_{50}$ was $5.49 \mu \mathrm{g} / \mathrm{mL}$ for L. amazonensis and $1.94 \mu \mathrm{g} / \mathrm{mL}$ for $L$. chagasi. BleuTV also inhibited growth of the epimastigote form of T. cruzi (Figure 5); after five days of culture, the $\mathrm{IC}_{50}$ value was $1.14 \mu \mathrm{g} / \mathrm{mL}$. The effects of inhibition were dose-dependent, and the cells lost their characteristic morphology, lacking flagella and a spherical format (data not shown). BleuLAAO did not have any inhibitory effect.
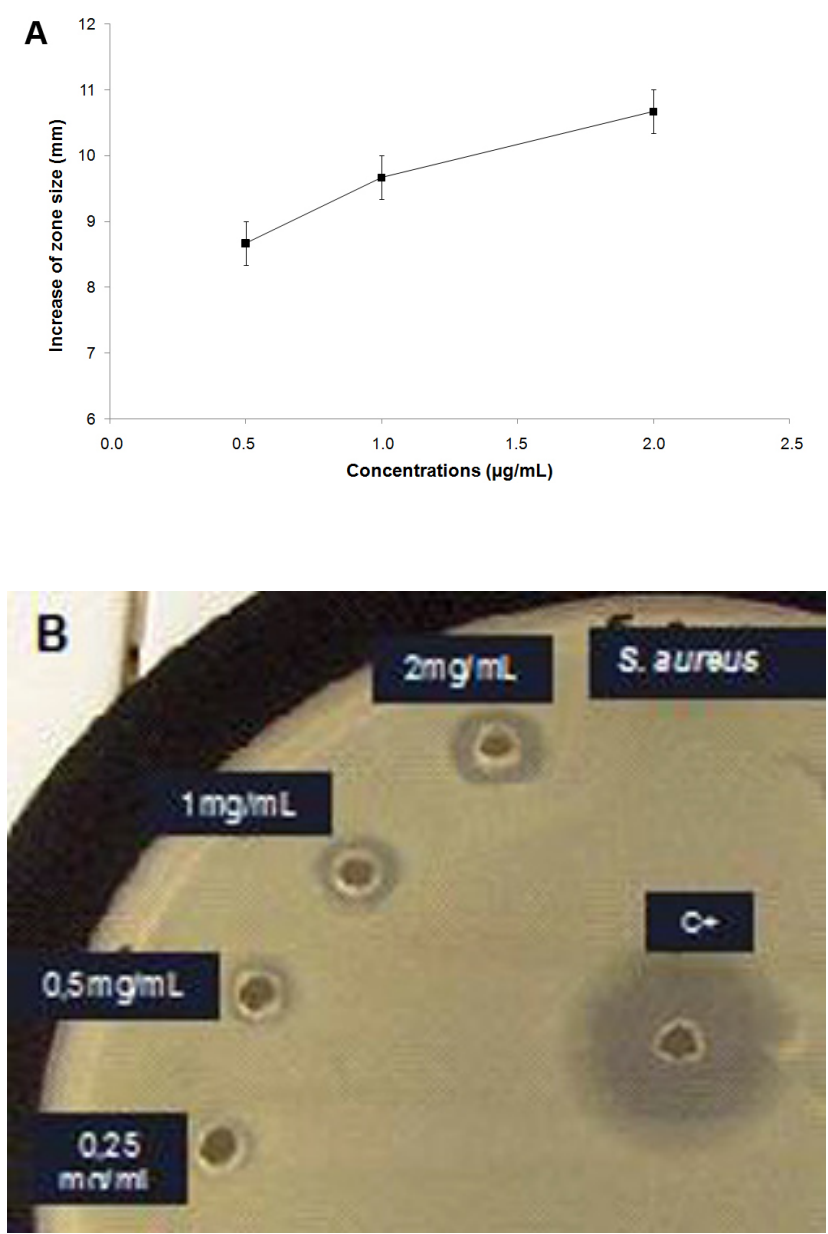

Figure 2. Antibacterial activity of BleuTV in a diskdiffusion assay. (A, B) Antibacterial activity of BleuTV against $S$. aureus ( $\square)$. The values represent the mean \pm SEM of three independent assays performed in triplicate. The inhibition zone is given in $\mathrm{mm}$, including the $5 \mathrm{~mm}$ diameter of the well, after 18 hours of incubation. BleuTV: whole venom of $B$. leucurus. $\mathrm{C}^{-}$: PBS. 


\section{Cytotoxicity in Murine Macrophages}

BleuTV significantly reduced cell viability at $200 \mu \mathrm{g} / \mathrm{mL}\left(\mathrm{IC}_{50}=175.5 \mu \mathrm{g} / \mathrm{mL}\right.$ ) (Figure 6). The venom promoted morphological alterations in the cell surface, including membrane rupture and significant cellular lysis, when compared with the control group (Figure 7). BleuLAAO did not have any cytotoxic effect at the studied concentrations.

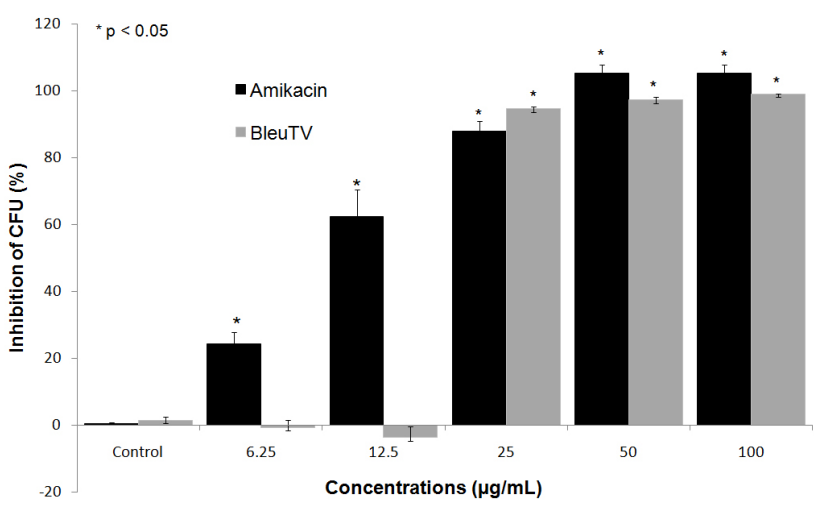

Figure 3. Profiles of the inhibition of $S$. aureus by $B$. leucurus venom and amikacin (100, 50, 25, 12.5 and $6.25 \mu \mathrm{g} / \mathrm{mL}$ ). After incubation, bacterial growth was measured spectrophotometrically $(490 \mathrm{~nm})$. The values represent the mean \pm SEM of three independent assays performed in triplicate. ${ }^{*} p$ $<0.05$ when compared with the corresponding control group.

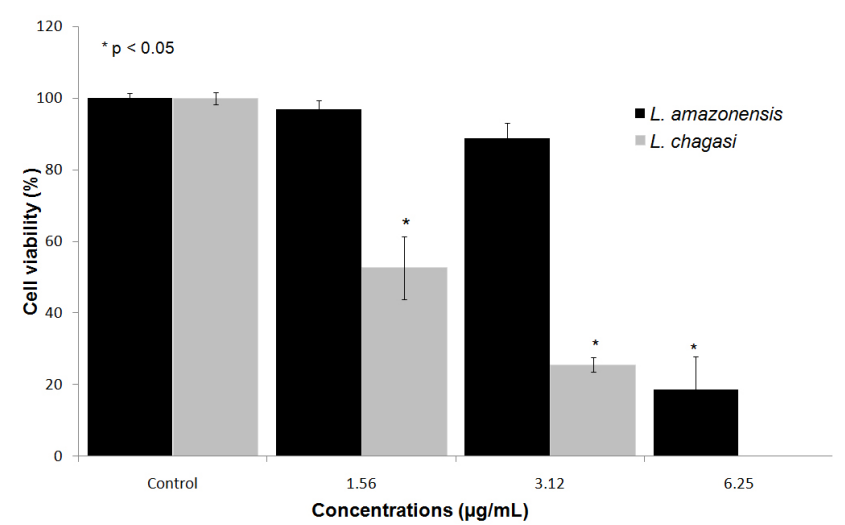

Figure 4. Leishmanicidal activity of different concentrations of BleuTV on promastigote forms of L. amazonensis and L. chagasi. The initial cell density was $1 \times 10^{6}$ cells $/ \mathrm{mL}$. The graph presents mean \pm SEM $(n=3)$. BleuTV: whole venom of B. leucurus. ${ }^{*} p<$ 0.05 compared to the corresponding control group.

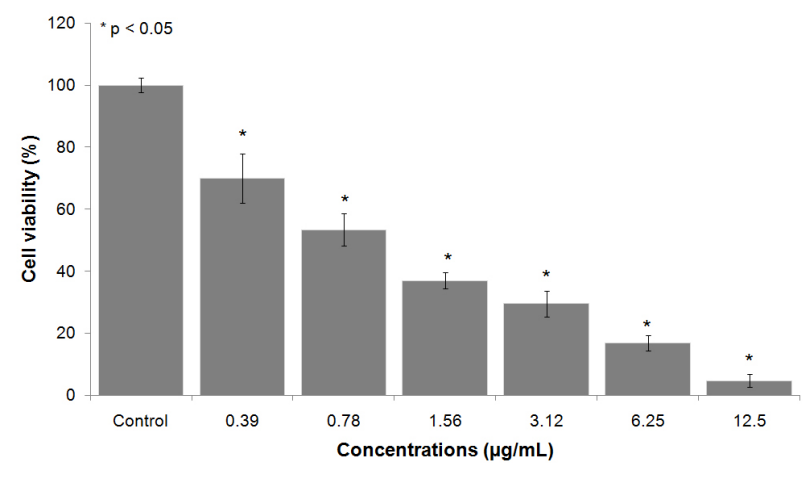

Figure 5. Trypanocidal activity against epimastigote forms of T. cruzi, after five days of culture with different concentrations $(12.5-0.39 \mu \mathrm{g} / \mathrm{mL})$ of $B$. leucurus venom. The initial cell density was $1 \times 10^{6}$ cells $/ \mathrm{mL}$. The graph presents mean \pm SEM $(n=3)$. ${ }^{*} p<0.05$ compared to the corresponding control group.

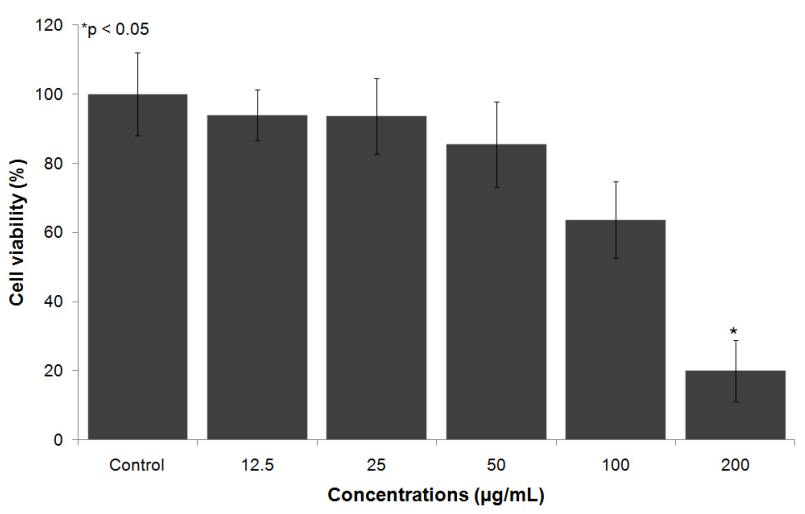

Figure 6. Cytotoxic effect of different concentrations (200-12.5 $\mu \mathrm{g} / \mathrm{mL}$ ) of $B$. leucurus venom on murine macrophages. The initial cell density was $1 \times 10^{6}$ cells/ $\mathrm{mL}$. The graph presents mean \pm SEM $(n=3) .{ }^{*} p<0.05$ compared to the corresponding control group.
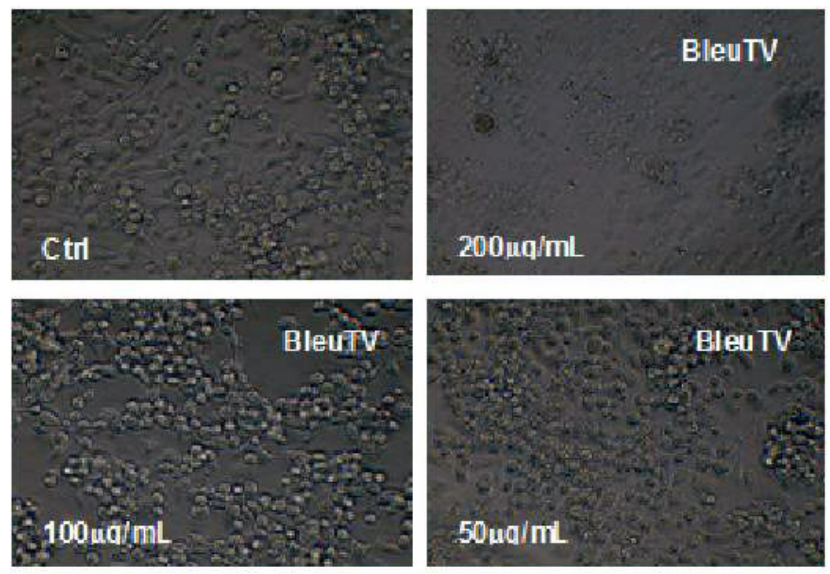

Figure 7. Morphological changes of murine macrophages after exposure to BleuTV. Ctrl: macrophages treated with PBS served as negative control. BleuTV: B. leucurus whole venom. 


\section{DISCUSSION}

Snake venoms are often targeted for new therapeutic uses, and many pharmacologic activities and biotechnological applications for these venoms have been described. Thus, the isolation and functional characterization of venom components provides a basis for understanding the mechanisms and/or future molecular models of venom action $(21,22)$.

The N-terminal amino acid sequence of BleuLAAO showed high conservation to other LAAOs, such as those from the Bothrops insularis and Bothrops moojeni venoms.

Some studies have demonstrated an antimicrobial effect of snake venoms and their isolated compounds. In the present study, BleuTV had a significant antibacterial effect on S. aureus, with an MIC equal to the MLC. According to Tavares (23), the value of MLC should be no greater than one or two-fold the MIC value. A large difference between these values suggests that the microorganism is tolerant to the drug, which does not cause therapeutic difficulties for most infections in patients with preserved immunity because the bacteriostatic activity of the drug is sufficient to allow the immune system to eliminate the microorganism.

In this study, antiparasitic effects against L. amazonensis, L. chagasi and T. cruzi were observed for BleuTV. Venoms from Crotalus durissus terrificus and Crotalus durissus cascavella have antiparasitic activity against Xantomonas axonopodis $p v$. passiflorae, and L. amazonensis $(10,24)$. Bothrops venoms also have antimicrobial activity against Leishmania major, T. cruzi and $S$. aureus $(25,11)$.

L-amino acid oxidases of snake venoms (svLAAO) present antimicrobial activity against several microorganisms. LAAOs from Crotalus adamanteus and Bothrops asper have an antibacterial effect against $S$. aureus and Proteus mirabilis (26). svLAAOs from Bothrops venoms also have antimicrobial effects (27-29). svLAAO from $B$. pirajai inhibited the growth of Pseudomonas aeruginosa and E. coli (29). Bactericidal action has also been described for svLAAOs from B. alternatus (30). In our studies, parasites lost their characteristic morphology in the presence of BleuTV.
LAAO from B. jararacussu is significantly active against Leishmania sp. (31). The whole venom of B. moojeni and its LAAO are significantly active against the promastigote forms of L. amazonensis, $L$. chagasi and $L$. panamensis, with $\mathrm{IC}_{50}$ values around $1 \mu \mathrm{g} / \mathrm{mL}$; the hydrogen peroxide generated is a strong inducer of apoptosis, causing oxidative stress, initiating disruption of membranes and cytoplasm and, consequently, cell death (32). Some authors have observed that the antimicrobial action of this enzyme is significantly reduced by catalase, suggesting the importance of enzymatically-produced hydrogen peroxide for biological activity $(31,33,34)$. BleuLAAO had no cytotoxic effect on any microorganism studied or on macrophages, which suggests that this fraction does not produce hydrogen peroxide in sufficient quantities at the studied concentrations of enzyme.

The alarming growth of microbial resistance to common therapeutic agents has drawn attention to infectious diseases. These diseases, which are mainly parasitic such as leishmaniasis and Chagas disease, are considered neglected and affect a wide portion of Brazilian populations and other developing countries that have difficulty accessing treatment. In addition, the available treatment options have limited effectiveness and high levels of toxicity. The identification of substances from natural sources with therapeutic potential is an important alternative. Many natural products demonstrate biological activities, including antimicrobial and antiparasitic effects, and snake venom may be a similarly relevant source of antimicrobials. Once molecules with the potential to inhibit microorganisms are identified, chemical modification techniques can be used to develop synthetic analogues with adequate pharmacological and toxicological characteristics.

In conclusion, our results suggest that $B$. leucurus venom contains some substances of therapeutic value, but LAAO is not responsible for the inhibitory effect of the whole venom.

\section{ACKNOWLEDGEMENTS}

The authors are thankful to Bruna Regina dos Santos for her technical assistance.

\section{COPYRIGHT}

(C) CEVAP 2010 


\section{SUBMISSION STATUS}

Received: June 7, 2010.

Accepted: October 21, 2010.

Abstract published online: October 22, 2010.

Full paper published online: November 30, 2010.

\section{CONFLICTS OF INTEREST}

There is no conflict.

\section{FINANCIAL SOURCE}

This work was supported by the Brazilian research agencies The National Council for Scientific and Technological Development (CNPq) and Coordination for the Improvement of Higher Education Personnel (CAPES).

\section{ETHICS COMMITTEE APPROVAL}

The present study was approved by the Animal Ethics Committee of the Federal University of Ceará (process n. 17/09).

\section{CORRESPONDENCE TO}

ALICE MARIA COSTA MARTINS,
Departamento de Análises Clínicas e Toxicológicas, Faculdade de Farmácia, Universidade Federal do Ceará, Rua Capitão Francisco Pedro, 1210, Fortaleza, CE, 60.420970, Brasil. Phone: +55853366 8263. Fax: +55 853366 8292. Email: martinsalice@gmail.com.

\section{REFERENCES}

1. Queiroz GP, Pessoa LA, Portaro FC, Furtado Mde F, Tambourgi DV. Interspecific variation in venom composition and toxicity of Brazilian snakes from Bothrops genus. Toxicon. 2008;52(8):842-51.

2. Pal SK, Gomes A, Dasgupta SC, Gomes A. Snake venom as therapeutic agents: from toxin to drug development. Indian J Exp Biol. 2002;40(12):1353-8.

3. Porto BN, Telli CA, Dutra TP, Alves LS, Bozza MT, Fin CA, et al. Biochemical and biological characterization of the venoms of Bothriopsis bilineata and Bothriopsis taeniata (Serpentes: Viperidae). Toxicon. 2007;50(2):270-7.

4. Kini RM. Venom phospholipase $\mathrm{A}_{2}$ enzymes: structure, function and mechanism. Chichester, UK: John Wiley \& Sons; 1997. p. 1-511.

5. Bailey P, Wilce J. Venom as a source of useful biologically active molecules. Emerg Med (Fremantle). 2001;13(1):28-36.

6. Du XY, Clemetson KJ. Snake venom L-amino acid oxidases. Toxicon. 2002;40(6): 659-65.

7. Braga MD, Martins AM, Amora DN, de Menezes $\mathrm{DB}$, Toyama MH, Toyama DO, et al. Purification and biological effects of L-amino acid oxidase isolated from Bothrops insularis venom. Toxicon. 2008;51(2):199-207.

8. Stábeli RG, Amui SF, Sant'ana CD, Pires MG, Nomizo A, Monteiro MC, et al. Bothrops moojeni myotoxin-II, a Lys49-phospholipase $\mathrm{A}_{2}$ homologue: an example of function versatility of snake venom proteins. Comp Biochem Physiol C Toxicol Pharmacol. 2006;142(3-4):371-81.

9. Rodrigues VM, Marcussi S, Cambraia RS, de Araújo AL, Malta-Neto NR, Hamaguchi A, et al. Bactericidal and neurotoxic activities of two myotoxic phospholipase $\mathrm{A}_{2}$ from Bothrops neuwiedi pauloensis snake venom. Toxicon. 2004; 44(3):305-14.

10. Passero LF, Tomokane TY, Corbett CE, Laurenti $\mathrm{MD}$, Toyama MH. Comparative studies of the anti-leishmanial activity of three Crotalus durissus spp. venoms. Parasitol Res. 2007;101(5):1365-71.

11. Ciscotto P, Machado de Avila RA, Coelho EAF, Oliveira J, Diniz CG, Farias LM, et al. Antigenic, microbicidal and antiparasitic properties of an L-amino acid oxidase isolated from Bothrops jararaca snake venom. Toxicon. 2009;53(3):33041.

12. Toyama MH, Toyama Dde O, Passero LF, Laurenti MD, Corbett CE, Tomokane TY, et al. Isolation of a new $\mathrm{L}$-amino acid oxidase from Crotalus durissus cascavella venom. Toxicon. 2006;47(1):47-57.

13. Schagger $H$, von Jagow $G$. Tricine-sodium dodecyl sulfate-polyacrylamide gel electrophoresis for the separation of proteins in the range from 1 to 100 kDa. Anal Biochem. 1987;166(2):368-79.

14. Kishimoto M, Takahashi T. A spectrophotometric microplate assay for L-amino acid oxidase. Anal Biochem. 2001;298(1):136-9.

15. de Oliveira DG, Toyama MH, Martins AM, Havt A, Nobre AC, Marangoni S, et al. Structural and biological characterization of a crotapotin isoform isolated from Crotalus durissus cascavella venom. Toxicon. 2003;42(1):53-62.

16. Watts JL, Shryock TR, Apley M, Bade DJ, Brown SD, Gray JT, et al . Performance standards for antimicrobial disk susceptibility tests; approved standard - eighth edition. NCCLS (National Committee for Clinical Laboratory Standards). 2003;28(8):19087-1898.

17. Hecht DW, Citron DM, Cox M, Jacobus N, Jenkins SG, Onderdonk A, et al. Methods for dilution antimicrobial susceptibility tests for bacteria that grow aerobically; approved standard - sixth edition. NCCLS (National Committee for Clinical Laboratory Standards). 2003;27(2):19087-1898.

18. de Oliveira MR, Tafuri WL, Nicoli JR, Vieira EC, Melo MN, Vieira LQ. Influence of microbiota in 
experimental cutaneous leishmaniasis in Swiss mice. Rev Inst Med Trop São Paulo. 1999;41(2):8794.

19. Camargo EP. Growth and differentiation in Trypanosoma cruzi. I. Origin of metacyclic trypanosomes liquid media. Rev Inst Med Trop São Paulo. 1964;6(1):93-100.

20. Mosmann T. Rapid colorimetric assay for cellular growth and survival: application to proliferation and citotoxicity assays. J Immunol Methods. 1983;65(1-2):55-63.

21. Harvey AL, Bradley KN, Cochran SA, Rowan EG, Pratt JA, Quillfeldt, JA, et al. What can toxins tell us for drug discovery? Toxicon. 1998;36(11):163540.

22. Mortari MR, Cunha AO, Ferreira LB, dos Santos WF. Neurotoxins from invertebrates as anticonvulsants: from basic research to therapeutic application. Pharmacol Ther. 2007;114(2):171-83.

23. Tavares W. Antibióticos e quimioterápicos para o clínico. São Paulo: Atheneu; 2007. 586 p.

24. Oliveira DG, Toyama MH, Novello JC, Beriam LO, Marangoni S. Structural and functional characterization of basic $\mathrm{PLA}_{2}$ isolated from Crotalus durissus terrificus venom. J Protein Chem. 2002;21(3):161-8.

25. Gonçalves AR, Soares MJ, de Souza W, DaMatta RA, Alves EW. Ultra structural alterations and growth inhibition of Trypanosoma cruzi and Leishmania major induced by Bothrops jararaca venom. Parasitol Res. 2002;88(7):598-602.

26. Perumal Samy R, Gopalakrishnakone P, Thwin MM, Chow TK, Bow H, Yap EH, et al. Antibacterial activity of snake, scorpion and bee venoms: a comparison with purified venom phospholipase $\mathrm{A}_{2}$ enzymes. J Appl Microbiol. 2007;102(3):650-9.

27. Tempone AG, Andrade Jr HF, Spencer PJ, Lourenço CO, Rogero JR, Nascimento N. Bothrops moojeni venom kills Leishmania spp. with hydrogen generated by its L-amino acid oxidase. Biochem Biophys Res Commun. 2001;280(3):620-4.
28. Costa Torres AF, Dantas RT, Toyama MH, Diz Filho E, Zara FJ, Rodrigues de Queiroz MG, et al. Antibacterial and antiparasitic effects of Bothrops marajoensis venom and its fractions: phospholipase $\mathrm{A}_{2}$ and L-amino acid oxidase. Toxicon. 2010; 55(4):795-804.

29. Izidoro LFM, Ribeiro MC, Souza GRL, Sant'Anna CD, Hamaguchi A, Homsi-Brandeburgo MI, et al. Biochemical and functional characterization of an L-amino acid oxidase isolated from Bothrops pirajai snake venom. Bioorg Medic Chem. 2006;14(20):7034-43.

30. Stábeli RS, Marcussi S, Carlos GB, Pietro RC, Selistre-de-Araújo HS, Giglio JR, et al. Platelet aggregation and antibacterial effects an L-amino acid oxidase purified from Bothrops alternatus snake venom. Bioorg Med Chem. 2004;12(11):2881-6.

31. França SC, Kashima S, Roberto PG, Marins M, Ticli FK, Pereira JO, et al. Molecular approaches for structural characterization of Bothrops L-amino acid oxidases with antiprotozoal activity: cDNA cloning, comparative sequence analysis, and molecular modeling. Biochem Biophys Res Com. 2007;355(2):302-6.

32. Stiles BG, Sexton FW, Weinstein SA. Antibacterial effects of different snake venoms: purification and characterization of antibacterial proteins from Pseudechis australis (Australian king brown or mulga snake) venom. Toxicon. 1991;29(9):112941.

33. Wei JF, Wei Q, Lu QM, Tai H, Jin Y, Wang WY, et al. Purification, characterization and biological activity of L-amino acid oxidase from Trimeresurus mucrosquamatus venom. Acta Biochim Biophys Sin. 2003;35(2):219-24.

34. Lu QM, Wei Q, Jin Y, Wei JF, Wang WY, Xiong YL. L-amino acid oxidase from Trimeresurus jerdonii snake venom: purification, characterization, platelet aggregation-inducing and antibacterial effects. J Nat Toxins. 2002;11(4):345-52. 